\title{
'Staggers' in Australian alpaca (Vicugna pacos)
}

\author{
N.G. SAMPAIO ${ }^{1}$, M. GISHEN ${ }^{2}$, K.F.M. REED ${ }^{3}$, M. BROWN ${ }^{4}$, \\ D. GREGORY 5 and K.A. MUNYARD ${ }^{1}$ \\ ${ }^{1}$ Biomedical Sciences, Curtin University of Technology, GPO Box U1987, Perth WA 6845 \\ ${ }^{2}$ Shingleback Ridge Alpacas, PO Box 69, Hahndorf SA 5245 \\ ${ }^{3}$ Reed Pasture Science, 430 Beveridge Road, Hamilton Vic. 3300 \\ ${ }^{4}$ Ausmara Alpacas, 39 Gordon Grove, Menzies Creek Vic. 3159 \\ ${ }^{5}$ Chiverton Alpacas, PO Box 496, Cowes Vic. 3922 \\ rps@eftel.net.au
}

\begin{abstract}
In a random survey of 107 alpaca producers across Australia, $23 \%$ had observed staggers over the previous 3 years with signs usually persisting 3-4 months. Observations were mainly from south-eastern Australia. Staggers was largely associated with the presence of perennial ryegrass $(\mathrm{P}<0.01)$ and phalaris $(\mathrm{P}<0.02)$; not with annual ryegrass or paspalum. Depending on season, 9$12 \%$ of alpaca exposed to perennial ryegrass exhibited staggers. Significantly more of the herds that contained staggers-affected animals had alpaca that exhibited panting and crowding into dams or streams $(\mathrm{P}<0.01)$, ill-thrift $(\mathrm{P}<0.001)$, low fertility $(\mathrm{P}<0.02)$ and early death of cria $(\mathrm{P}<0.06)$ compared with unaffected herds. The number of herds showing signs of panting and crowding into dams were significantly higher where perennial ryegrass was present $(\mathrm{P}<0.001)$ but such differences were not significant for the other three grasses. Weanling alpaca were the more likely to stagger than adults $(\mathrm{P}<0.001)$. The annual cost to treat staggers was $\$ 96$ per affected alpaca.
\end{abstract}

Keywords: Neotyphodium lolii, perennial ryegrass, perennial ryegrass toxicosis, phalaris staggers, heat stress, fertility

\section{Introduction}

Many plant species cause neurotoxic disorders in herbivores with signs such as staggers. In Australia, perennial ryegrass toxicosis (PRGT) is the most common cause of such problems. It can be fatal and is known to occur in sheep, cattle, horses, deer, alpaca and many other herbivores (Miles et al. 1998; Holmes et al. 1999). PRGT is commonly recognised as "ryegrass staggers" and is associated with ingestion of perennial ryegrass (PRG) (Lolium perenne) infected with the microscopic fungus Neotyphodium lolii (Mackintosh \& Orr 1993; Miles et al. 1998). This symbiotic endophyte produces neurotoxins and ergot alkaloids, mainly during late spring to autumn (Reed et al. 2001). Other common grasses causing staggers include annual ryegrass (Lolium rigidum), paspalum (Paspalum dilatatum) and phalaris (Phalaris aquatica) (Miles et al. 1998). For dairy cattle grazing endophytic PRG, milk production was reduced by $14 \%$ in autumn relative to endophyte-free PRG, although only one cow exhibited staggers (Valentine et al. 1993). Other "sub-clinical" effects including heat stress, lowered fertility, ill-thrift and scouring have occurred in controlled experiments when sheep or cattle grazing on PRG

Table 1 Number of farms surveyed and reporting staggers in alpaca in different states of Australia.

\begin{tabular}{lccc}
\hline State & No. of farms surveyed & $\begin{array}{c}\text { No. reporting } \\
\text { staggers }\end{array}$ & \% of farms affected \\
\hline Queensland & 4 & 0 & 0 \\
New South Wales & 38 & 2 & 5 \\
Victoria & 35 & 15 & 43 \\
Tasmania & 3 & $6 \mathrm{v}$ & 66 \\
South Australia & 16 & 0 & 38 \\
Western Australia & 11 & 25 & 0 \\
\hline Total & 107 & 23 \\
\hline
\end{tabular}

Table 2 Number (and percentage) of staggers-affected alpaca observed by respondents in New South Wales, Victoria and South Australia.

\begin{tabular}{|c|c|c|c|c|c|c|}
\hline \multirow[t]{2}{*}{ State } & \multicolumn{2}{|c|}{----- 2004 ----- } & \multicolumn{2}{|c|}{---- 2005 ----- } & \multicolumn{2}{|c|}{---- 2006* ----- } \\
\hline & Unaffected & Affected & Unaffected & Affected & Unaffected & Affected \\
\hline New South Wales & 1387 & $19(1.4 \%)$ & 1334 & $18(1.3 \%)$ & 1087 & $23(2.1 \%)$ \\
\hline Victoria & 815 & $17(2.0 \%)$ & 774 & $35(4.3 \%)$ & 688 & 27 (3.8\%) \\
\hline South Australia & 282 & $18(6.0 \%)$ & 355 & $34(8.7 \%)$ & 204 & $31(13.2 \%)$ \\
\hline Total & 2484 & $54(2.1 \%)$ & 2463 & $87(3.4 \%)$ & 1979 & $81(3.9 \%)$ \\
\hline
\end{tabular}

* survey ended, mid-January 2006 
Table 3 Proportion of surveyed farms that recorded the presence of four species of grass in pasture, and the mean estimated contribution to pasture of each species.

\begin{tabular}{lcccc}
\hline Grass species & \multicolumn{2}{c}{$\begin{array}{l}\text { Farms with species present (\%) } \\
\text { Affected }\end{array}$} & Unaffected & \multicolumn{2}{c}{$\begin{array}{c}\text { Contribution to pasture (\%) } \\
\text { Affected }\end{array}$} & \begin{tabular}{c} 
Unaffected \\
\hline Perennial ryegrass
\end{tabular} & 76 & 36 & 40 & 15 \\
Annual ryegrass & 24 & 23 & 18 & 19 \\
Phalaris & 48 & 19 & 29 & 11 \\
Paspalum & 24 & 26 & 5 & 9 \\
\hline
\end{tabular}

Table 4 Age distribution of alpaca (cria (C), weanling (W) or adult (A)) on staggers-free farms (unaffected animals), exposed to toxins but not affected (alpaca on farms where at least one was affected) and exposed to toxins and affected (affected animals).

\begin{tabular}{|c|c|c|c|c|c|c|c|c|c|c|c|c|}
\hline \multirow[b]{2}{*}{ Alpaca } & \multicolumn{4}{|c|}{---------- 2006 ---------- } & \multicolumn{4}{|c|}{---------- 2005 ---------- } & \multicolumn{4}{|c|}{---------- 2004 ---------- } \\
\hline & Total & $\mathrm{C} 1$ & W & A & Total & C & W & A & Total & C & W & A \\
\hline \multirow[t]{2}{*}{ Unaffected } & 3972 & & 852 & 3120 & 3932 & & 872 & 3060 & 2978 & & 634 & 2344 \\
\hline & & -- & $21.5 \%$ & $78.5 \%$ & & -- & $22.2 \%$ & $78 \%$ & & -- & $21.3 \%$ & $78.7 \%$ \\
\hline \multirow[t]{2}{*}{ Exposed } & 929 & 75 & 162 & 692 & 927 & 81 & 172 & 674 & 1521 & 126 & 145 & 1250 \\
\hline & & $8.1 \%$ & $17.4 \%$ & $74.5 \%$ & & $8.7 \%$ & $18.6 \%$ & $72.7 \%$ & & $8.3 \%$ & $9.5 \%$ & $82.2 \%$ \\
\hline \multirow[t]{2}{*}{ Affected } & 55 & 4 & 31 & & 88 & 5 & 36 & & 99 & & & 43 \\
\hline & & $7.2 \%$ & $56.4 \%$ & $36.4 \%$ & & $5.7 \%$ & $40.9 \%$ & $53.4 \%$ & & $24.2 \%$ & $32.3 \%$ & $43.4 \%$ \\
\hline
\end{tabular}

${ }^{1}$ No data for unaffected farms.

with and without endophyte have been compared (eg. Easton et al. 1996; Fletcher et al. 1999; Keogh \& Blackwell 2001).

\section{Method}

A survey of staggers was conducted by telephone of 107 of the 2100 members of the Australian Alpaca Association (AAA), selected at random. The AAA represents over 70000 registered alpaca. A sample size lower limit of 92 members was required to achieve a $95 \%$ confidence limit at a $10 \%$ confidence interval for the information sought. The number of alpaca and presence of sheep or cattle was recorded for 2004, 2005 and 2006. Alpaca were classified as Huacaya or Suri breeds and by age. The survey recorded possible signs of PRGT including staggers, crowding into dams, panting in cool weather, reduced fertility, neo-natal losses, ill-thrift and scouring. Information was collected on the onset and duration, remedial action, estimates of treatment costs as well as the presence and contribution of the four most likely staggers-inducing grass species in their pasture. Chi square, Pearson's correlation and t-test analyses of data were conducted using JMP (SAS Institute), SYSTAT and SPSS (SPSS) programs.

\section{Results}

Farms for which at least one animal exhibited staggers in any year were classified as 'affected'. Eighty-two respondents reported no staggers on their farms while $25(23.4 \%)$ reported staggers (Table 1). The proportion of all alpaca surveyed that were observed with staggers was 3\% (Table 2). Seventy-six percent of affected farms identified perennial ryegrass in their pastures compared with $36 \%$ of unaffected farms (Table 3). Pearson's test showed a significant correlation between the presence of perennial ryegrass $(\mathrm{PRG})$ and the occurrence of staggers $(\mathrm{P}<0.001)$ (Table $3)$. In contrast to perennial ryegrass and phalaris, the incidence of staggers was not noticeably related to the presence of annual ryegrass and paspalum. The mean contribution of perennial ryegrass in the pasture was higher on affected farms than it was on unaffected farms. The next most common species present on affected farms was phalaris. The onset of signs in herds affected with staggers was reported in all months of the year, but mostly during January-March (Fig. 1). The mean duration of signs was 3.5 months (range 0.25-12.0) (Fig. 2).

For the 15 farms where other animal species were present, alpaca were considered more sensitive to the cause(s) of staggers than sheep or cattle - only two of these farms had other animals develop staggers - sheep in both cases. Occurrence of staggers differed among age groups (Table 4). In each of the 3 years of the survey, $>30 \%$ of affected animals on farms where staggers was recorded were weanlings, although this age group represented less than $20 \%$ of the alpaca herd. Over $95 \%$ of alpaca were Huacaya and the Chi square test showed that the difference between these and Suri in susceptibility to staggers was not significant. In describing the signs of staggers, $100 \%$ of respondents with affected alpaca reported poor coordination, $92 \%$ head tremors, $84 \%$ tripping or staggering, $32 \%$ spasms and $28 \%$ stock down in the paddock. Pearson's correlation test showed that affected farms reported a markedly higher occurrence of sub-clinical signs compared with unaffected farms (Table 5). The average annual cost of treatment for an affected alpaca was AUD\$96. For remedial action, $68 \%$ administered medication/nursing and $32 \%$ sought veterinary advice/action.

To examine the effect of climate on the occurrence of staggers, average annual rainfall at the nearest meteorological station was compared for affected and unaffected farms using the Student 
t-test. The average rainfall was significantly higher on farms that were affected by staggers in both South Australia and New South Wales (Table 6). This probably reflects the increased ability of perennial grasses to persist and grow with higher rainfall. Similarly the presence of annual ryegrass was associated with a significantly lower average annual rainfall (Table 7).

\section{Discussion}

Results of this survey confirm that staggers occurs frequently in alpaca in Australia, with an average of $23 \%$ of national herds affected. On farms where staggers was reported, $9.3 \%$ of the animals developed signs. Victoria, where perennial ryegrass is widely naturalised, showed a high incidence of staggers.
Tasmania and South Australia were also affected.

Of alpaca exposed to pasture containing PRG, 5.9\% developed staggers (Table 4). This is consistent with reports from southern Victoria where $5-10 \%$ of alpaca exposed to PRG developed clinical signs of PRGT that persisted for up to 3 months of the year (Reed \& Cummins 2003).

The month of onset and duration of staggers symptoms varied, but January, February and March were the most common. As shown by Barker et al. (1993), N. lolii produced more toxin when the host plant was moisture stressed (e.g. excessive heat or drought) than when it was not. The duration of the clinical signs most often lasted 3 to 4 months, although 5 of the 25 farms that were affected (two in SA and three in Victoria) reported symptoms

Table 5 Percentage of herds that demonstrated signs of possible sub-clinical effects of PRGT.

\begin{tabular}{lccccccc}
\hline & $\begin{array}{c}\text { Crowding } \\
\text { into dams }\end{array}$ & Panting & $\begin{array}{c}\text { Lowered } \\
\text { fertility }\end{array}$ & $\begin{array}{c}\text { Loss of } \\
\text { pregnancy }\end{array}$ & $\begin{array}{c}\text { Early } \\
\text { death of cria }\end{array}$ & III-thrift & Scouring \\
\hline Unaffected & 3.7 & 3.7 & 9.9 & 23.5 & 18.5 & 12.3 & 6.2 \\
Affected & 20.0 & 20.0 & 28.0 & 44.0 & 36.0 & 52.0 & 12.0 \\
P-value & 0.006 & 0.006 & 0.020 & 0.039 & 0.059 & 0.000 & 0.326 \\
\hline
\end{tabular}

Table 6 Mean annual rainfall $(\mathrm{mm})$ for affected and unaffected farms by states.

\begin{tabular}{lccc}
\hline State & Affected & Unaffected & P-value \\
\hline New South Wales & 1101 & 777 & 0.025 \\
Victoria & 814 & 802 & 0.873 \\
Queensland & - & 1321 & - \\
South Australia & 743 & 594 & 0.006 \\
Western Australia & - & 691 & - \\
\hline
\end{tabular}

Table 7 Average rainfall $(\mathrm{mm})$ for farms that recorded grass species as present or absent.

\begin{tabular}{lcccc}
\hline & Perennial ryegrass & Annual ryegrass & Phalaris & Paspalum \\
\hline Absent & 768 & 819 & 776 & 803 \\
Present & 821 & 708 & 842 & 761 \\
Significance & $\mathrm{NS}$ & $\mathrm{P}=0.003$ & $\mathrm{P}=0.051$ & $\mathrm{NS}$ \\
\hline
\end{tabular}

Figure 1 Number of farms by month when onset of staggers was first noticed in 2004-06

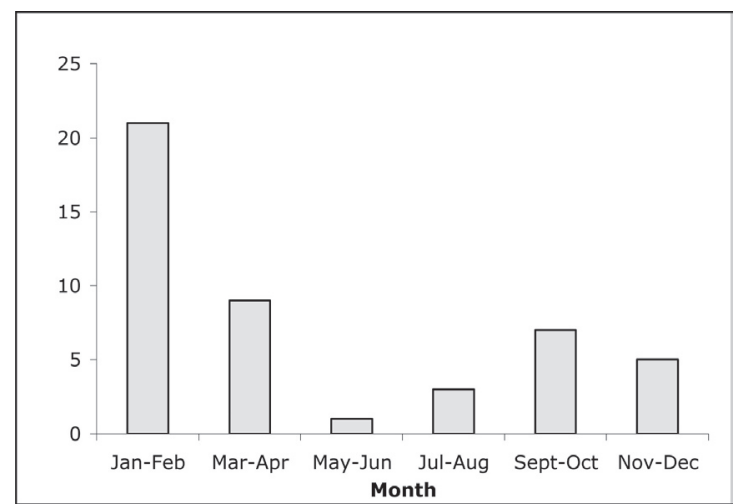

Figure 2 Number of farms by annual duration of staggers signs (months) in 2004-06.

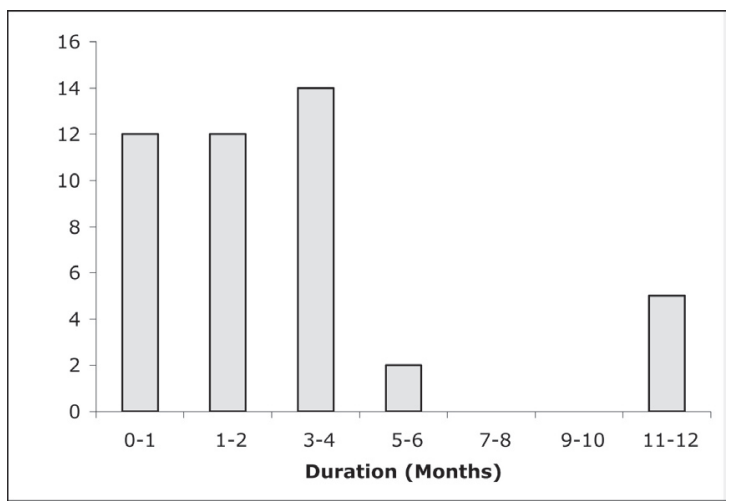


lasting 12 months. Such poor reversibility was occasionally noted in the southern Victorian alpaca (Reed \& Cummins 2003) and has not been observed in sheep and cattle. Alpaca may have low tolerance of PRG toxins. The greater susceptibility of young stock (Table 4) has often been noted in other species.

The most common signs associated with staggers were poor coordination; most producers also noted head tremors and tripping. Some reported animal spasms or having stock down in the paddock. These more serious symptoms were probably obviated in most cases, in contrast to extensively grazed sheep, by removing alpaca from the pasture and hand feeding them in yards at the onset of staggers. Most 'sub-clinical' signs were more prevalent in staggers-affected herds than in unaffected herds. This indicates that the loss of productivity and subsequent costs from staggers may be higher than can be estimated from the numbers of clinically affected animals. The estimated cost per head of sub-clinical and speculative effects in sheep is as high as $62 \%$ of the total cost of PRGT (Lean 2005). Credible measurement of the actual costs of PRGT awaits the conduct of carefully controlled experiments to measure performance of stock on pastures where perennial ryegrasses with and without toxin-producing endophytes are compared.

\section{ACKNOWLEDGEMENTS}

The Australian Alpaca Association for support and Kerryn Butler-Henderson for statistical advice.

\section{REFERENCES}

Barker, D.J.; Davies, E.; Lane, G.A.; Latch, G.C.M.; Nott, H.M.; Tapper, B.A. 1993. Effect of water deficit on alkaloid concentrations in perennial ryegrass endophyte associations. pp. 67-71. In: Proceedings of the 2nd International Symposium on Acremonium/Grass Interactions. Eds. Hume, D.E.; Latch, G.C.M.; Easton, H.S., AgResearch, Palmerston North, New Zealand.

Easton, H.S.; Lane, G.A.; Tapper, B.A.; Keogh, R.G.; Cooper, B.M.; Blackwell, M.; Anderson, M.; Fletcher, L.R. 1996. Ryegrass endophyte-related heat stress in cattle. Proceedings of the New Zealand Grassland Association 57: 37-41.

Fletcher, L.R.; Sutherland, B.L.; Fletcher, C.G. 1999. The impact of endophyte on the health and productivity of sheep grazing ryegrass-based pastures. pp. 11-17. In: Ryegrass endophyte: an essential New Zealand symbiosis. Grassland Research and Practice Series 7. New Zealand Grassland Association

Holmes, L.; Frame, N.; Frame, R.; Deff, J.; Lewis, G. 1999. Suspected tremorgenic mycotoxicosis (ryegrass staggers) in alpaca (Llama pacos) in the UK. The Veterinary Record 145: 462-463.

Keogh, R.G.; Blackwell, M.B. 2001. A three-year investigation of the performance of spring calving dairy cows grazing ryegrass-based pastures of high or low endophyte toxin status in Northland. Proceedings New Zealand Grassland Association 63: 209-214.

Lean G. 2005. Impact on sheep production of perennial ryegrass toxicosis. pp. 37-44. In: Perennial ryegrass toxicosis in Australia. Eds. Reed, K.F.M.; Page, S.W.; Lean, I. Meat and Livestock Australia, North Sydney.

Mackintosh, C.; Orr, M. 1993. Ryegrass staggers in alpaca? Veterinary Record 132: 120.

Miles, C.; di Menna, M.; Jacobs, S.; Garthwaite, I.; Lane, G.; Prestidge, R.; Marshall, S.; Wilkinson, H.; Schardl, C.; Ball, O.; Latch, G. 1998. Endophytic fungi in indigenous Australasian grasses associated with toxicity in livestock. Applied and Environmental Microbiology 42: 601-606.

Reed K.F.M.; McFarlane, N.M.; Walsh, J.R. 2001. Seasonal alkaloid concentration in perennial ryegrass dairy pasture. Proceedings of the 10th Australian Agronomy Conference, Hobart. www.regional.org.au/au/asa/2001/

Reed, K.F.M.; Cummins, L.J. 2003. Incidence of perennial ryegrass staggers among alpaca in Southern Victoria. pp. 1517. In: Australian Alpaca Association West. Victoria Region Newsletter, Issue 50.

Valentine, S.C.; Bartsch, B.D.; Carroll, P.D. 1993. Production and composition of milk by dairy cattle grazing high and low endophyte cultivars of perennial ryegrass. pp. 138-141. In: Proceedings of the 2nd International Symposium Acremonium/ Grass Interactions. Eds. Hume, D.E.; Latch, G.C.M.; Easton, H.S., AgResearch, Palmerston North, New Zealand. 